\title{
Spin transition centres linked by the nitroprusside ion. The cooperative transition in bis(2,6-bis(pyrazol-3-yl)- pyridine)iron(II) nitroprusside
}

\author{
Kristian H. Sugiyarto, $\dagger^{a}$ Wendy-Anne McHale, ${ }^{a}$ Donald C. Craig, ${ }^{a}$ A. David Rae, ${ }^{b}$ \\ Marcia L. Scudder ${ }^{a}$ and Harold A. Goodwin $* a$ \\ a School of Chemical Sciences, University of New South Wales, UNSW, Sydney 2052, \\ Australia. E-mail: H.Goodwin@unsw.edu.au \\ ${ }^{b}$ Research School of Chemistry, Australian National University, Canberra ACT 2601, Australia
}

Received 30th January 2003, Accepted 15th April 2003

First published as an Advance Article on the web 14th May 2003

The complex $\left[\mathrm{Fe}(3-\mathrm{bpp})_{2}\right]\left[\mathrm{Fe}(\mathrm{CN})_{5}(\mathrm{NO})\right](3-\mathrm{bpp}=2,6$-bis(pyrazol-3-yl)pyridine) undergoes an abrupt, thermallyinduced ${ }^{1} \mathrm{~A}_{1} \leftrightarrow{ }^{5} \mathrm{~T}_{2}$ spin transition associated with a narrow $(\sim 3 \mathrm{~K})$ hysteresis loop $\left(T_{1 / 2} \downarrow=181 \mathrm{~K} ; T_{1 / 2} \uparrow=184 \mathrm{~K}\right)$. The transition is accompanied by a change in crystallographic space group (P4/ncc at $294 \mathrm{~K}$; Pnca at $100 \mathrm{~K}$ ) along with a change in the average $\mathrm{Fe}-\mathrm{N}$ distance of $0.21 \AA$. The complex cation and anion are linked by hydrogen bonding involving each of the four pyrazolyl-NH moieties of each complex cation and the four equatorial cyano groups of each anion, resulting in layers of 4,4-nets. The hydrogen bonding remains essentially the same in both phases but the relative orientations of the cations and anions change significantly to allow for the change in the dimensions of the complex cation, accounting for the cooperativity associated with the spin change.

\section{Introduction}

Salts of the $\left[\mathrm{FeN}_{6}\right]^{2+}$ derivative of 2,6-bis(pyrazol-3-yl)pyridine (1) (3-bpp) are spin crossover systems and thus display remarkable electronic properties resulting from the spin state of the iron being delicately poised energetically between a singlet ${ }^{1} \mathrm{~A}_{1}$ (low-spin, LS) and a quintet ${ }^{5} \mathrm{~T}_{2}$ (high-spin, HS). The spin state is sensitive to perturbations in the physical conditions such as variations in temperature, pressure and light irradiation, as well as chemical modifications such as variation in the associated anion and in the degree of hydration in the salts. A number of salts $\left[\mathrm{Fe}(3-\mathrm{bpp})_{2}\right] \mathrm{X}_{2} \cdot n \mathrm{H}_{2} \mathrm{O}$ have been characterised and the general aspect that emerges is that under ambient conditions the spin state of the hydrated salts is a singlet and that of the anhydrous is a quintet. ${ }^{1,2}$ For both species spin transitions are observed, those for the former occurring above, and for the latter below, room temperature. Moreover, the nature of the transitions differs - those for the hydrates being continuous, while those for the latter are abrupt and associated with thermal hysteresis. These comments apply where $\mathrm{X}=\mathrm{BF}_{4}^{-}, \mathrm{NCS}^{-}$, $\mathrm{NCSe}^{-}, \mathrm{I}^{-}$. The behaviour of the triflate salt is somewhat distinct in that it crystallises as a trihydrate (which is essentially low-spin at room temperature) and this readily loses two molecules of water with the monohydrate being high-spin at room temperature and displaying a remarkable spin transition curve which reveals a very abrupt HS $\rightarrow$ LS change with decreasing, and a two-step LS $\rightarrow$ HS change with increasing temperature. The latter is displaced markedly to higher temperature, leading to an extraordinarily broad hysteresis loop. The remaining water molecule is lost at higher temperature but this results, surprisingly, in the restoration of a LS fraction at room temperature and a continuous increase in this at low temperatures, without any evident thermal hysteresis when the sample is cycled through the temperature range. ${ }^{3}$ In addition to these properties, the relatively long lifetimes (at unusually high temperatures) of photo-induced metastable states of salts of $\left[\mathrm{Fe}(3-\mathrm{bpp})_{2}\right]^{2+}$ place these systems amongst the most remarkable of spin crossover species. ${ }^{4}$

It has been proposed that the highly cooperative nature of the transitions observed in the anhydrous salts and in

$\dagger$ Present address: State University of Yogyakarta, Yogyakarta 55281, Indonesia.

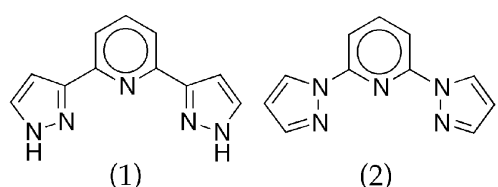

$\left[\mathrm{Fe}(3-\mathrm{bpp})_{2}\right]\left[\mathrm{CF}_{3} \mathrm{SO}_{3}\right]_{2} \cdot \mathrm{H}_{2} \mathrm{O}$ arises from propagation of the structural changes associated with the spin change in the complex cation throughout the lattice via hydrogen bonding interactions involving the uncoordinated $>\mathrm{NH}$ groups of the pyrazolyl moieties and the anions (or, for the triflate monohydrate, the anions and the water). The crystal structures of a number of hydrated salts (LS) have revealed extensive hydrogen-bonded networks involving linkage through the pyrazolyl $>\mathrm{NH}$ groups. It has not, however, been possible so far to obtain the crystal structure of a species in which water has been lost and a highly abrupt transition results. Obviously, the structure of such a species would be highly relevant to an understanding of the likely mechanism for the cooperativity displayed. Crystal structure determination of these species has been precluded by breakdown of the crystal lattice accompanying the loss of water. Structural information has been obtained from EXAFS measurements but this relates only to the immediate environment of the metal atom and not to the overall lattice packing. ${ }^{5}$

Some doubt regarding hydrogen bonding promoting the cooperativity of the transitions in these systems has arisen in the light of the properties of the isomeric system $\left[\mathrm{Fe}(1-\mathrm{bpp})_{2}\right] \mathrm{X}_{2}$ (1-bpp = 2,6-bis(pyrazol-1-yl)pyridine (2)) for which hydrogen bonding of the kind which has been identified in the hydrated salts of $\left[\mathrm{Fe}(3-\mathrm{bpp})_{2}\right]^{2+}$ is not possible. Despite this, the properties of $\left[\mathrm{Fe}(3-\mathrm{bpp})_{2}\right]\left[\mathrm{BF}_{4}\right]_{2}$ and $\left[\mathrm{Fe}(1-\mathrm{bpp})_{2}\right]\left[\mathrm{BF}_{4}\right]_{2}$ are remarkably similar, both salts undergoing abrupt transitions below room temperature with associated thermal hysteresis loops. ${ }^{6}$

It is feasible that the origin of the cooperativity could lie in aryl-aryl interactions which are facilitated by the 3-bpp systems adopting a general form of crystal packing for bis(planartridentate)metal systems which allows for offset face-to-face and edge-to-face interactions. ${ }^{7}$ This packing motif is present in the structure of $\left[\mathrm{Fe}(1-\mathrm{bpp})_{2}\right]\left[\mathrm{BF}_{4}\right]_{2}$ too, although it has been suggested that for this system the cooperativity may be related to a partial ordering of the anion orientation near the transition temperature. Aryl-aryl interactions have been proposed to account for the cooperativity in other spin crossover systems 
where they are present and where there is no other obvious means of propagation of the structural changes. ${ }^{8}$ The determination of the lattice characteristics which promote cooperativity in spin crossover systems is one of the primary goals of much current activity in the area since this feature is essential for molecular bistability, the property which is likely to be exploited in practical applications of such systems. ${ }^{9}$

In a continuing effort to understand the origin of the cooperative nature of the transitions in $\left[\mathrm{Fe}(3-\mathrm{bpp})_{2}\right] \mathrm{X}_{2}$ salts one of our goals has been to obtain structural data for a system above and below the spin transition temperature. Our previous efforts have been thwarted principally by the breakdown of the crystal lattice on loss of water from a hydrated species to give the cooperative spin transition system. In the present work we report the properties of $\left[\mathrm{Fe}(3-\mathrm{bpp})_{2}\right]\left[\mathrm{Fe}(\mathrm{CN})_{5}(\mathrm{NO})\right]$. This species crystallises from water as an anhydrous compound, is high-spin at room temperature and undergoes a strongly cooperative transition to low-spin at low temperature, the thermally-induced cycle $\mathrm{HS} \longrightarrow \mathrm{LS} \longrightarrow \mathrm{HS}$ enclosing a hysteresis loop. Moreover it has been possible to grow crystals for detailed structural analysis, enabling the determination of the structure above and below the transition temperatures and revealing the likely origin of the cooperativity.

\section{Results and discussion}

\section{Electronic properties of $\left[\mathrm{Fe}(3-\mathrm{bpp})_{2}\right]\left[\mathrm{Fe}(\mathrm{CN})_{5}(\mathrm{NO})\right]$}

The bulk samples of $\left[\mathrm{Fe}(3-\mathrm{bpp})_{2}\right]\left[\mathrm{Fe}(\mathrm{CN})_{5}(\mathrm{NO})\right]$ were obtained by the slow addition of aqueous sodium nitroprusside solution to aqueous $\left[\mathrm{Fe}(3-\mathrm{bpp})_{2}\right] \mathrm{Cl}_{2}$. Crystals for the structural analysis were grown by slow diffusion of these solutions. At room temperature the salt is bright yellow, typical for a species containing high-spin $\left[\mathrm{Fe}(3-\mathrm{bpp})_{2}\right]^{2+}$, while at low temperatures it is deep red-brown, characteristic of low-spin species. ${ }^{1}$ The spin transition in this salt was characterised by the measurement of the temperature-dependence of the magnetism and the Mössbauer spectrum. At $298 \mathrm{~K}$ the magnetic moment is $5.4 \mu_{\mathrm{B}}$, while at $99 \mathrm{~K}$ it is $1.3 \mu_{\mathrm{B}}$, indicative of a virtually complete, thermallyinduced singlet $\left({ }^{1} \mathrm{~A}_{1}\right) \leftrightarrow$ quintet $\left({ }^{5} \mathrm{~T}_{2}\right)$ transition in this temperature range. The variation in the magnetic moment with temperature is shown in Fig. 1 which reveals the abrupt nature of the transition and the appearance of a narrow hysteresis loop.

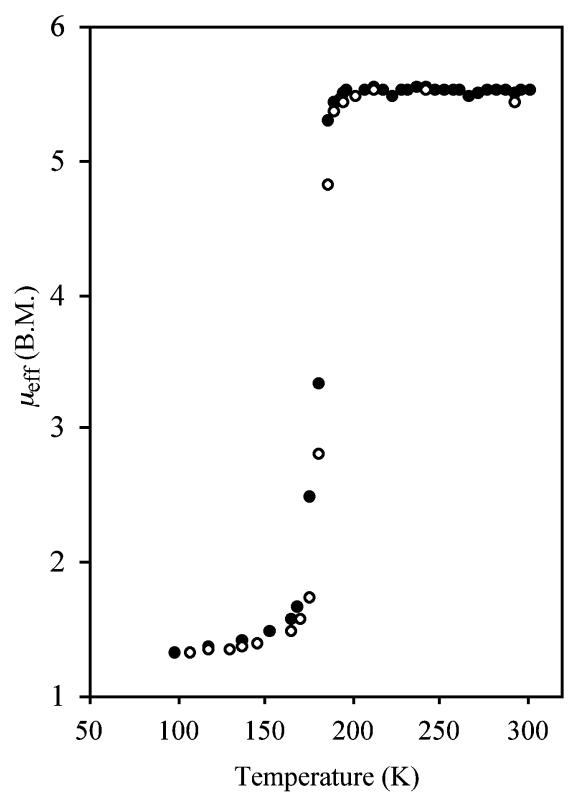

Fig. 1 Temperature-dependence of the magnetism of [Fe(3-bpp $\left.)_{2}\right]$ $\left[\mathrm{Fe}(\mathrm{CN})_{5}(\mathrm{NO})\right]$. Filled circles: decreasing temperature; open circles: increasing temperature.
Table 1 Mössbauer spectral parameters $\left(\mathrm{mm} \mathrm{s}^{-1}\right)$ for $\left[\mathrm{Fe}(3-\mathrm{bpp})_{2}\right]-$ $\left[\mathrm{Fe}(\mathrm{CN})_{5}(\mathrm{NO})\right]$

\begin{tabular}{lrlllll}
\hline Ion & $T / \mathrm{K}$ & \multicolumn{1}{c}{$\Delta E_{\mathrm{Q}}{ }^{a}$} & \multicolumn{1}{l}{$\delta_{\mathrm{i} . \mathrm{s}}{ }^{b}$} & $\Gamma^{c}$ & $\gamma^{d}$ & $I^{e}$ \\
\hline$\left[\mathrm{Fe}(3-\mathrm{bpp})_{2}\right]^{2+}$ & 298 & 2.09 & 0.96 & 0.36 & 0.93 & 25.3 \\
& 80 & 0.65 & 0.42 & 0.57 & 0.93 & 21.1 \\
{$\left[\mathrm{Fe}(\mathrm{CN})_{5}(\mathrm{NO})\right]^{2-}$} & 298 & 1.84 & -0.28 & 0.23 & 0.07 & 3.09 \\
& 80 & 1.90 & -0.22 & 0.30 & 0.07 & 2.76
\end{tabular}

${ }^{a}$ Quadrupole splitting. ${ }^{b}$ Isomer shift (relative to metallic iron at $298 \mathrm{~K}$ ). ${ }^{c}$ Line width at half height. ${ }^{d}$ Area fraction. ${ }^{e}$ Percentage transmission.

From the magnetic measurements the transition temperatures are estimated as $T_{1 / 2} \downarrow=181 \mathrm{~K}$ and $T_{1 / 2} \uparrow=184 \mathrm{~K}$, giving the width of the hysteresis loop $\Delta T_{1 / 2}=3 \mathrm{~K}$. The actual values for the transition temperatures were not exactly reproducible for different samples and showed a variation of about $\pm 3 \mathrm{~K}$ for a range of eight independently prepared samples. The variation in $\Delta T_{1 / 2}$ was $\pm 1 \mathrm{~K}$. This is not considered unusual. ${ }^{10}$ Mössbauer spectral data clearly indicate a change in spin state as the source of the temperature-variation in the magnetic moment. The spectra are somewhat more complex than those of other $\left[\mathrm{Fe}(3-\mathrm{bpp})_{2}\right]^{2+}$ systems previously reported because of the presence of iron in both the cation and the anion and the partial overlap of spectral features of each ion. In addition, asymmetry is evident in the spectra to varying extents. This may arise from orientation effects or can be ascribed to the GoldanskiiKaryagin effect. These problems were minimised by the measurement of the spectra of the species containing the cation enriched to $50 \%$ in ${ }^{57} \mathrm{Fe}$ and also that containing the cation enriched to $100 \%$ in ${ }^{54} \mathrm{Fe}$. The former allowed the parameters due to the cationic species to be determined with good precision since its contribution dominated the spectrum, while in the latter the contribution of the nitroprusside ion only was evident. Relevant spectra are shown in Fig. 2 and the spectral parameters are listed in Table 1. Those for the complex cation are consistent with values obtained for previously described $\left[\mathrm{Fe}(3-\mathrm{bpp})_{2}\right] \mathrm{X}_{2}$ systems and those for the nitroprusside ion are normal ( $c f$., for example, $\Delta E_{\mathrm{Q}}=1.88 \mathrm{~mm} \mathrm{~s}^{-1}$ and $\delta_{\text {i.s }}=$

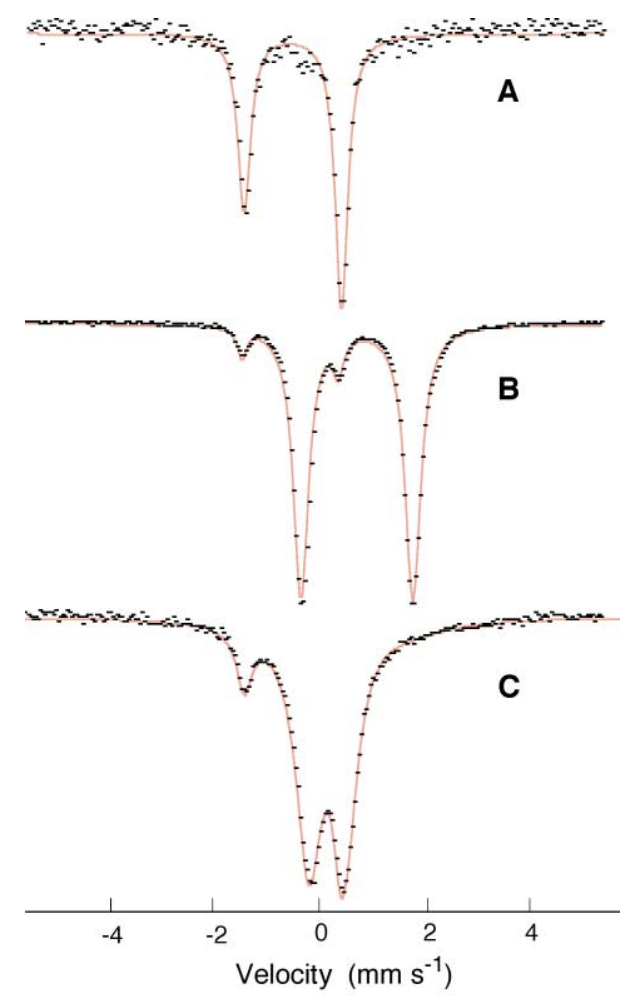

Fig. 2 Mössbauer spectra of $\left[\mathrm{Fe}(3-\mathrm{bpp})_{2}\right]\left[\mathrm{Fe}(\mathrm{CN})_{5}(\mathrm{NO})\right]$ : (A) at $298 \mathrm{~K}$ (sample enriched to $100 \%$ in ${ }^{54} \mathrm{Fe}$ ); (B) at $298 \mathrm{~K}$ (sample enriched to $50 \%$ in ${ }^{57} \mathrm{Fe}$ ); (C) at $80 \mathrm{~K}$ (sample enriched to $50 \%$ in ${ }^{57} \mathrm{Fe}$ ). 


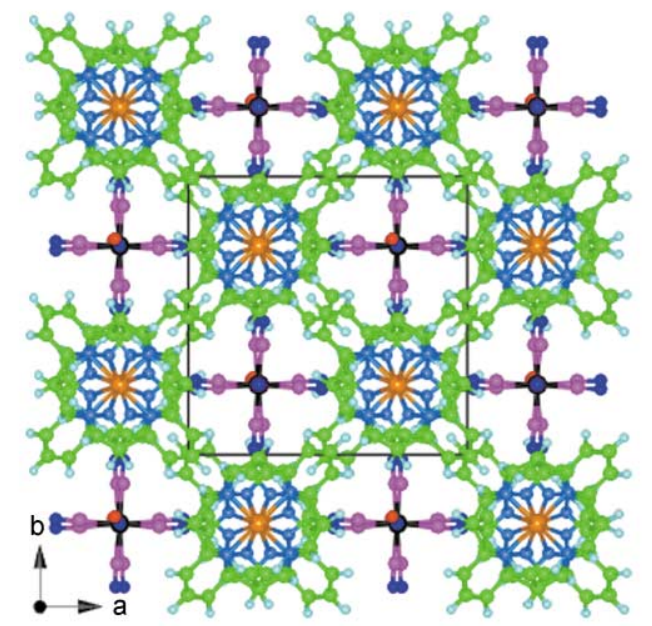

(a)

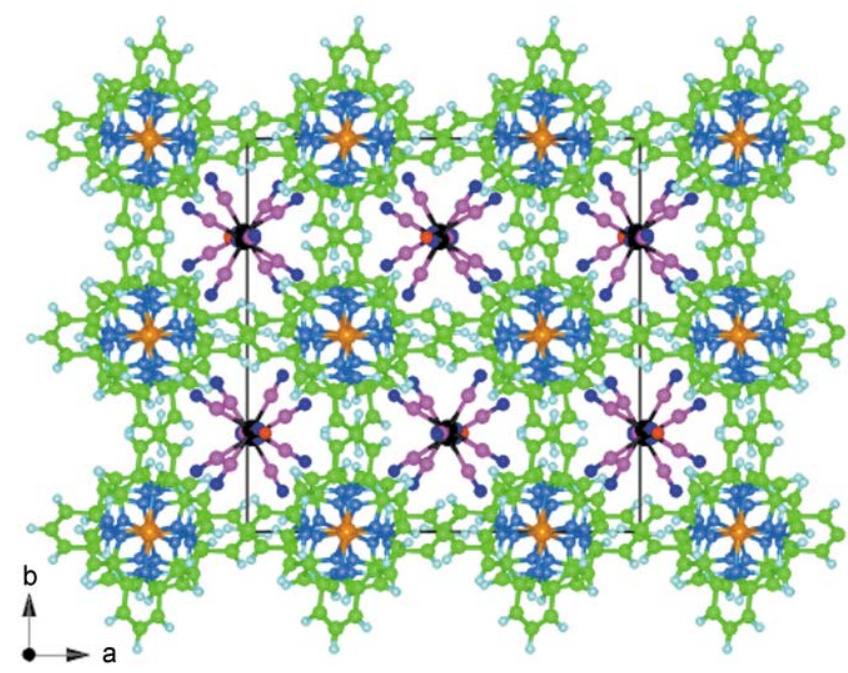

(c)

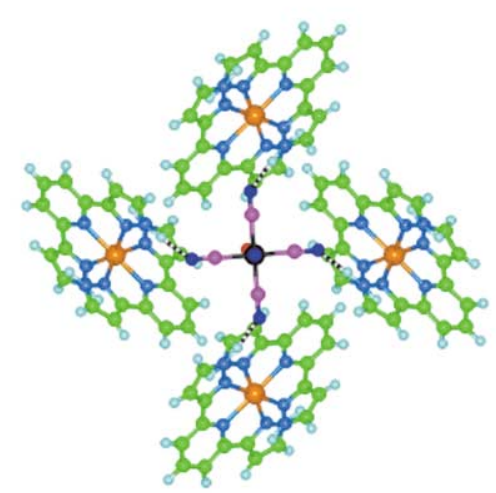

(b)

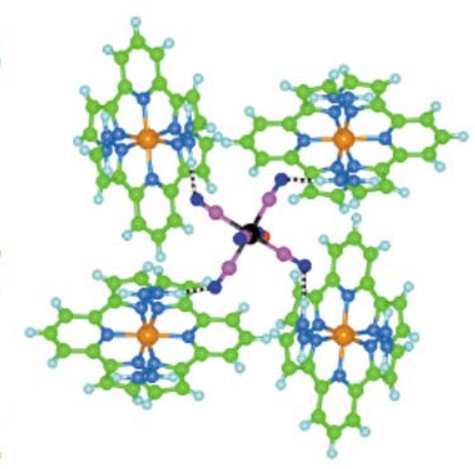

(d)

Fig. 4 The unit cell projection of (a) the room-temperature tetragonal and (c) the low-temperature pseudo-tetragonal (orthorhombic) structure of $\left[\mathrm{Fe}(3-\mathrm{bpp})_{2}\right]\left[\mathrm{Fe}(\mathrm{CN})_{5}(\mathrm{NO})\right]$. In both structures, the hydrogen bonded layer is perpendicular to $c$. (b) and (d) show enlarged views of the hydrogen bonding of a single anion in each structure. Rotation of the room-temperature structure (a and b) by $45^{\circ}$ about $c$ yields views which may be compared to those of the low-temperature structure (c and d).

transition. This tilting allows the layers to approach one another more closely than at $294 \mathrm{~K}$, reflected in the observed increase in density $\left(1.50\right.$ and $1.56 \mathrm{~g} \mathrm{~cm}^{-3}$ at 294 and $100 \mathrm{~K}$, respectively).

The alignment of the nitroprusside ions in columns along $c$ differs in the two phases. In the high-spin phase they are almost eclipsed whereas in the low-spin they are distinctly staggered, the rotation angle of the $\mathrm{Fe}(\mathrm{CN})_{4}$ plane in alternate layers being $\sim 30^{\circ}$ (see Fig. 4(a) and (c)). Fig. 5(a) and (b) illustrate the similarity of the cation chains along $c$ in the two structures, together with the change in orientation of the anions along the stacks. In both structures the inter-anion $\mathrm{NO} \cdots \mathrm{NC}$ distances are unusually short $(\sim 2.8 \AA)$ but this may simply be a corollary of the packing requirements determined by the strong > $\mathrm{NH}_{\text {cation }} \cdots \mathrm{NC}_{\text {anion }}$ hydrogen bonding. The $\mathrm{N}-\mathrm{H}$ hydrogen bonding distances are all $\sim 1.8 \AA$ at both temperatures.

In addition to hydrogen bonding there are aryl-aryl interactions involving the cations both within and between the layers. These interactions are essentially the same at both temperatures. There are edge-to-face interactions between cations within each layer, where the edge from the pyridyl ring interacts with two faces, one from each of two ligands on the adjacent cations. The acceptor faces are pyrazole rings. There are also edge-to-face interactions with poor geometry between adjacent cations in each chain. A cycle of four such interactions links pairs of cations along the chain. It is noteworthy that the typical "terpyridine embrace" of many bis(planar tridentate) systems ${ }^{7}$ is not present in these structures.

\section{Conclusion}

The overall contraction in the molecular dimensions accompanying the $\mathrm{HS} \rightarrow$ LS change in $\left[\mathrm{Fe}(3-\mathrm{bpp})_{2}\right]\left[\mathrm{Fe}(\mathrm{CN})_{5}(\mathrm{NO})\right]$ necessitates an orientational change in the hydrogen bonding centres on the complex cations. An accompanying change in the orientation of the nitroprusside ions allows the basic features of the hydrogen bonding to be maintained. It seems most probable that this concerted change and the cooperativity of the spin change are inter-related. In some respects the role of the nitroprusside ion in this system, with four equatorial cyano groups linking the spin transition centres, is similar to that of the planar tetracyanometallates $\left(\left[\mathrm{M}(\mathrm{CN})_{4}\right]^{2-}(\mathrm{M}=\mathrm{Ni}, \mathrm{Pd}, \mathrm{Pt})\right)$ which bridge $\mathrm{Fe}(\mathrm{py})_{2}{ }^{2+}$ units in the Hoffmann-type lattices which also display cooperative spin transitions, ${ }^{12}$ the essential difference being that the bridging is via covalent bonds rather than the hydrogen bonds of the present system. Some preliminary studies of $\left[\mathrm{Fe}(3-\mathrm{bpp})_{2}\right]\left[\mathrm{M}(\mathrm{CN})_{4}\right]$ salts, which form readily, have been undertaken but to date structural data have not been obtained. A structure very similar to that of [Fe(3-bpp) $\left.)_{2}\right]$ $\left[\mathrm{Fe}(\mathrm{CN})_{5}(\mathrm{NO})\right]$ would be predicted. Similarly the trans dicarbonyl-tetracyanoferrate(II) ion, $\left[\mathrm{Fe}(\mathrm{CN})_{4}(\mathrm{CO})_{2}\right]^{2-}$, which forms layer-type networks bridged through the cyano groups ${ }^{13}$ may 


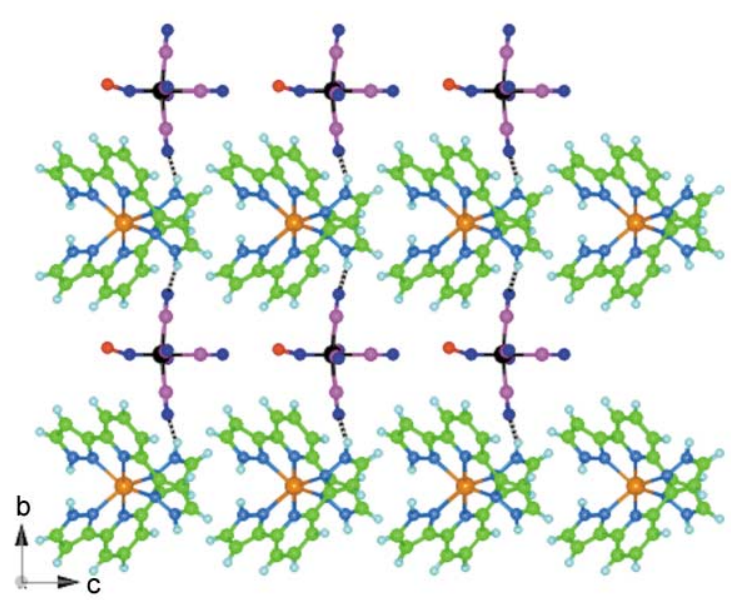

(a)

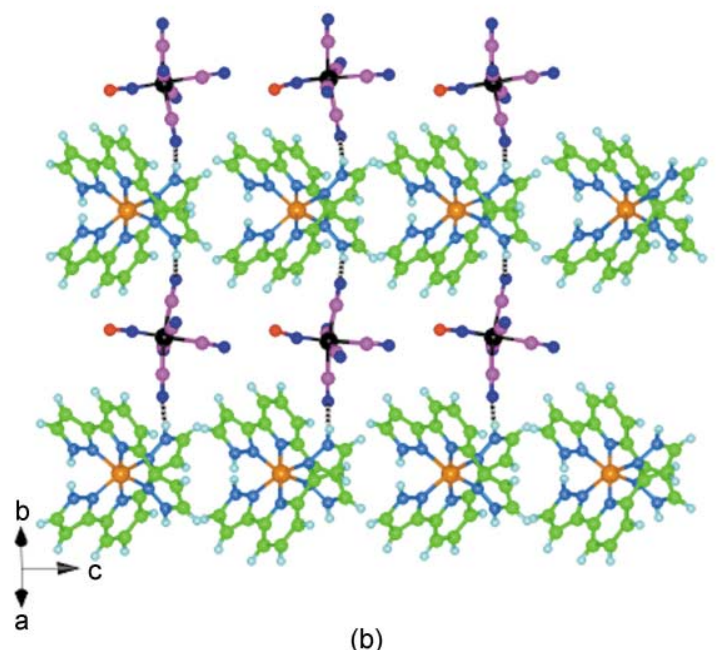

(b)

Fig. 5 Comparison of the hydrogen bonding chains of cations and anions in (a) the room-temperature and (b) the low-temperature structures viewed along $a$ and the $a b$ diagonal, respectively. Note the similarity of the cation chains, but the difference in the anion chain at the two temperatures.

well prove a useful linking moiety for the $\left[\mathrm{Fe}(3-\mathrm{bpp})_{2}\right]^{2+}$ species Finally it may be anticipated that the nitroprusside salt of the bis(2,6-bis(1,2,4-triazol-3-yl)pyridine)iron(II) ion (also a spin transition system) ${ }^{14}$ would present scope for hydrogen bonding similar to that of the present system, with the four noncoordinated $>\mathrm{NH}$ groups of each complex cation.

Details of the effects of irradiation on the electronic properties of $\left[\mathrm{Fe}(3-\mathrm{bpp})_{2}\right]\left[\mathrm{Fe}(\mathrm{CN})_{5}(\mathrm{NO})\right]$ will be published separately. ${ }^{15}$

\section{Experimental}

\section{Preparation of bulk samples of $\left[\mathrm{Fe}(3-b p p)_{2}\right]\left[\mathrm{Fe}(\mathrm{CN})_{5}(\mathrm{NO})\right]$}

In an atmosphere of nitrogen solid 3-bpp (0.43 g, 2 mmol) was added to a solution of freshly prepared iron(II) chloride tetrahydrate $(0.2 \mathrm{~g}, 1 \mathrm{mmol})$ in de-aerated water $(25 \mathrm{~mL})$ and the mixture gently warmed until the ligand had all reacted. The solution was then filtered and a warm solution of sodium nitroprusside dihydrate $(0.6 \mathrm{~g}$, excess $)$ in water $(25 \mathrm{~mL})$ was slowly added. A bright yellow crystalline precipitate of the product separated almost immediately. This was washed with cold water and dried in vacuum (Found: Fe, 15.9; C, 46.5; $\mathrm{H}$, 2.9; N, 32.5; Calc. for $\mathrm{C}_{27} \mathrm{H}_{18} \mathrm{~N}_{16} \mathrm{OFe}_{2}$ : Fe, 16.1; C, 46.7; H, 2.6; $\mathrm{N}, 32.3 \%$ ). Enriched iron(II) chloride was prepared by reaction of the appropriate iron isotope as metallic iron with a slight excess of $0.1 \mathrm{~mol} \mathrm{~L}^{-1} \mathrm{HCl}$ and repeated evaporation of the solution under nitrogen.

\section{Physical measurements}

Mössbauer spectra were recorded with a constant acceleration spectrometer in transmission mode, together with an Oxford Instruments cryostat and ITC-4 temperature control unit. The isomer shift values are relative to the midpoint of the iron spectrum at room temperature. The spectral parameters (Table 1) were extracted from a least squares fit of the data to Lorentzian line shapes. Magnetic data (corrected for diamagnetic contributions) were collected on a Newport variable-temperature Gouy balance calibrated with $\mathrm{CoHg}(\mathrm{NCS})_{4}$.

\section{Crystallography}

Crystals of $\left[\mathrm{Fe}(3-\mathrm{bpp})_{2}\right]\left[\mathrm{Fe}(\mathrm{CN})_{5}(\mathrm{NO})\right]$ were grown by slow diffusion of solutions of $\left[\mathrm{Fe}(3-\mathrm{bpp})_{2}\right] \mathrm{Cl}_{2}$ (prepared in situ as above) and sodium nitroprusside in separate arms of an $\mathrm{H}$-cell.

\section{Crystal data for room-temperature $\left[\mathrm{Fe}(3-\mathrm{bpp})_{2}\right]\left[\mathrm{Fe}(\mathrm{CN})_{5}(\mathrm{NO})\right]$}

$\mathrm{C}_{22} \mathrm{H}_{18} \mathrm{FeN}_{10} \cdot \mathrm{C}_{5} \mathrm{FeN} \mathrm{N}_{6} \mathrm{O}, M=694.2$, tetragonal, space group $P 4 / n c c, a=b=13.346(3), c=17.273(5) \AA, V=3077(1) \AA^{3}, D_{c}=$ $1.50 \mathrm{~g} \mathrm{~cm}^{-3}, Z=4, \mu_{\mathrm{Mo}}=0.991 \mathrm{~mm}^{-1}, 2 \theta_{\max }=50^{\circ}$, min. and max. transmission factors 0.80 and $0.89, T=294 \mathrm{~K}$. The number of reflections was 875 considered observed out of 1361 unique data. Final residuals $R, R_{\mathrm{w}}$ were $0.034,0.041$ for the observed data.

\section{Crystal data for low-temperature $\left[\mathrm{Fe}(3-b p p)_{2}\right]\left[\mathrm{Fe}(\mathrm{CN})_{5}(\mathrm{NO})\right]$}

$\mathrm{C}_{22} \mathrm{H}_{18} \mathrm{FeN}_{10} \cdot \mathrm{C}_{5} \mathrm{FeN}_{6} \mathrm{O}, M=694.2$, orthorhombic, space group PncalPncb twin, $a=18.8716(2), b=18.8716(2), c=16.6791(3)$ $\AA, V=5940.1(1) \AA^{3}, D_{\mathrm{c}}=1.56 \mathrm{~g} \mathrm{~cm}^{-3}, Z=8, \mu_{\mathrm{Mo}}=1.03 \mathrm{~mm}^{-1}$, $2 \theta_{\max }=55^{\circ}$, min. and max. transmission factors 0.90 and 0.83 , $T=100 \mathrm{~K}$. The number of reflections was 5694 considered observed out of 7104 unique data. Final residuals $R, R_{\mathrm{w}}$ were $0.044,0.058$ for the observed data.

\section{Structure determinations}

For the room-temperature structure, reflection data were measured with an Enraf-Nonius CAD-4 diffractometer in $\theta / 2 \theta$ scan mode using graphite-monochromated molybdenum radiation ( $\lambda=0.7107 \AA)$. Data were corrected for absorption using the analytical method of de Meulenaer and Tompa ${ }^{16}$ and for any decomposition. Reflections with $I>2 \sigma(I)$ were considered observed. The structure was determined by direct phasing and Fourier methods. Hydrogen atoms were included in calculated positions and were assigned thermal parameters equal to those of the atom to which they were bonded. Reflection weights used were $1 / \sigma^{2}\left(F_{\mathrm{o}}\right)$, with $\sigma\left(F_{\mathrm{o}}\right)$ being derived from $\sigma\left(I_{\mathrm{o}}\right)=\left[\sigma^{2}\left(I_{\mathrm{o}}\right)+\right.$ $\left.\left(0.04 I_{\mathrm{o}}\right)^{2}\right]^{1 / 2}$. The weighted residual is defined as $R_{\mathrm{w}}=\left(\Sigma w \Delta^{2} /\right.$ $\left.\Sigma w F_{\mathrm{o}}{ }^{2}\right)^{1 / 2}$. Atomic scattering factors and anomalous dispersion parameters were from International Tables for X-ray Crystallography. ${ }^{17}$ Structure solution was by SIR $92^{18}$ and anisotropic refinement used RAELS. ${ }^{19}$ The Fe atom of the cation was located on a 222 site $(3 / 4,1 / 4,1 / 4)$, while that of the anion was on a 4 -fold axis at $(1 / 4,1 / 4, z)$ with disorder of the coordinated NO.

Data for the low-temperature structure were recorded from the crystal used for the room-temperature determination. A Nonius Kappa CCD area detector diffractometer was used with molybdenum radiation $(\lambda=0.7107 \AA)$. The determination of the low-temperature structure proved problematic. Absences were consistent with either twinned PcnalPncb or twinned PncalPcnb. The $Z=8$, PcnalPncb option would have the cations at four non-equivalent sites of 222 symmetry and their equivalents. The $Z=8$, PncalPcnb option would have the cations at two non-equivalent sites of 2 symmetry, viz. (1/4, 1/2, $z)$ and $\left(3 / 4,1 / 2, z^{\prime}\right)$ and their equivalents. The anions are on a general position and its equivalents in both instances. The 
$z$ displacement of cations is only allowed by the correct space group choice.

The final refinement invoked twinning in the orthorhombic space group Pnca with a twin ratio of $0.497(1): 0.503$. The rings of each of the ligands of each cation were constrained to be planar, the four five-membered rings were constrained to be equal and the two six-membered rings were constrained to have equal local $m m 2$ symmetry relative to the Fe to which they were attached. The anisotropic atom displacement parameters were refined using rigid body $T L X$ parameterisations. The cations were site symmetry restricted ${ }^{20}$ and so 9 parameters per site were used rather than 15. An extra libration parameter was used to define the disordered $\mathrm{O}$ attached to the $\mathrm{N}$ of the anion.

Comprehensive description of the procedures adopted in the refinement of the low-temperature structure will be published elsewhere. ${ }^{21}$

CCDC reference numbers 202880 (294 K structure) and 202881 (100 K structure).

See http://www.rsc.org/suppdata/dt/b3/b301218b/ for crystallographic data in CIF or other electronic format.

\section{Acknowledgements}

We gratefully acknowledge support for this work from the Australian Research Council.

\section{References}

1 K. H. Sugiyarto and H. A. Goodwin, Aust. J. Chem., 1988, 41, 1645 K. H. Sugiyarto, D. C. Craig, A. D. Rae and H. A. Goodwin, Aust. J. Chem., 1994, 47, 869.

2 K. H. Sugiyarto, M. L. Scudder, D. C. Craig and H. A. Goodwin, Aust. J. Chem., 2000, 53, 755.

3 Th. Buchen, P. Gütlich, K. H. Sugiyarto and H. A. Goodwin, Chem.-Eur. J., 1996, 2, 1134; K. H. Sugiyarto, K. Weitzner, D. C. Craig and H. A. Goodwin, Aust. J. Chem., 1997, 50, 869.

4 Th. Buchen, P. Gütlich and H. A. Goodwin, Inorg. Chem., 1994, 33, 4573; S. Marcen, L. Lecren, L. Capes, H. A. Goodwin and J.-F. Létard, Chem. Phys. Lett., 2002, 358, 87.
5 R. Lübbers, G. Nowitzke, H. A. Goodwin and G. Wortmann, J. Phys. IV Fr., 1997, 7, C2.

6 J. M. Holland, J. A. McAllister, Z. Lu, C. A. Kilner, M. ThorntonPett and M. A. Halcrow, Chem. Commun., 2001, 577; J. M. Holland, J. A. McAllister, C. A. Kilner, M. Thornton-Pett, A. J. Bridgeman and M. A. Halcrow, J. Chem. Soc., Dalton Trans., 2002, 548; V. A. Money, I. R. Evans, M. A. Halcrow, A. E. Goeta and J. A. K. Howard, Chem. Commun., 2003, 158.

7 M. L. Scudder, H. A. Goodwin and I. G. Dance, New J. Chem., 1999, 23, 695.

8 G. Juhász, S. Hayami, O. Sato and Y. Maeda, Chem. Phys. Lett., 2002, 364, 164; R. Boca, M. Boca, L. Dlhan, K. Falk, H. Fuess, W. Haase, R. Jarosciak, B. Papankova, F. Renz, M. Vrbova and R. Werner, Inorg. Chem., 2001, 40, 3025; J. F. Létard, H. Daubric, C. Cantin, J. Kliava, Y. A. Bouhedja, O. Nguyen and O. Kahn, Mol. Cryst. and Liq. Cryst., 1999, 335, 495; Z. L. Zhong, J-Q. Tao, Z. Yu, C-Y. Dun, Y-J. Liu and X-Z. You, J. Chem. Soc., Dalton Trans., 1998, 327.

9 O. Kahn and C. J. Martinez, Science, 1998, 279, 44.

10 E. König, G. Ritter, S. K. Kulshreshtha, J. Waigel and H. A. Goodwin, Inorg. Chem., 1984, 23, 1896.

11 M. E. Garcia Posse, M. A. Juri, P. J. Aymonino, O. E. Piro, H. A. Negri and E. E. Castellano, Inorg. Chem., 1984, 23, 948.

12 V. Niel, J. M. Martinez-Agudo, M. C. Muñoz, A. B. Gaspar and J. A. Real, Inorg. Chem., 2001, 40, 3838; T. Kitazawa, Y. Gomi, M. Takahashi, M. Takeda, M. Enomoto, A. Miyazaki and T. Enoki, J. Mater. Chem., 1996, 6, 119.

13 J. Jiang and S. A. Koch, Chem. Commun., 2002, 1724.

14 K. H. Sugiyarto, D. C. Craig, A. D. Rae and H. A. Goodwin, Aust. J. Chem., 1993, 46, 1269.

15 F. Renz, P. Gütlich and H. A. Goodwin, unpublished work

16 J. De Meulenaer and H. Tompa, Acta Crystallogr., 1965, 19, 1014.

17 International Tables for X-Ray Crystallography, ed. J. A. Ibers and W. C. Hamilton, Kynoch Press, Birmingham, 1974, vol. 4.

18 A. Altomare, M. C. Burla, M. Camalli, G. Cascarano, C. Giacovazzo, A. Guagliardi and G. Polidori, J. Appl. Crystallogr., 1994, 27, 435.

19 A. D. Rae, RAELS - A comprehensive constrained least squares refinement program, Australian National University, Canberra, 2000 .

20 A. D. Rae, Acta Crystallogr., Sect. A., 1975, 31, 560-574.

21 A. D. Rae, unpublished work. 